\title{
periferio
}

\section{DESBARATANDO EL LENGUAJE ESCOLAR}

\author{
Silvia Duschatzky ${ }^{1}$ \\ Facultad Latinoamericana de Ciencias Sociales (FLACSO) Sede Argentina
}

\section{Resumen}

El punto de vista escolar impide estar en los problemas. Pero la escuela habla en sus problemas, en lo ínfimo, en sus costados inentendibles para el universo representacional. Abandonar lenguaje y el punto de vista escolar; pensar el afuera, la presencia de lo no escolar; recuperar lo que allí hay de moviente, su textura sensible, el plano de lo desconocido. Pensar la escuela como efecto, y no como premisa. Abrir, a partir de la formulación de algunas proposiciones, umbrales de investigación que no devienen prescripción sino un proyecto que investiga de qué se trata lo comun y de qué lo educativo.

Palabras clave: lenguaje escolar; punto de vista escolar; lo no escolar

\footnotetext{
1 Magíster en Sociología de la Cultura y Análisis Cultural (IDAES-UNSAM), Investigadora principal del Programa Políticas, Lenguajes y Subjetividades en Educación (Área Educación FLACSO Argentina). E-mail: silss2012@gmail.com
} 


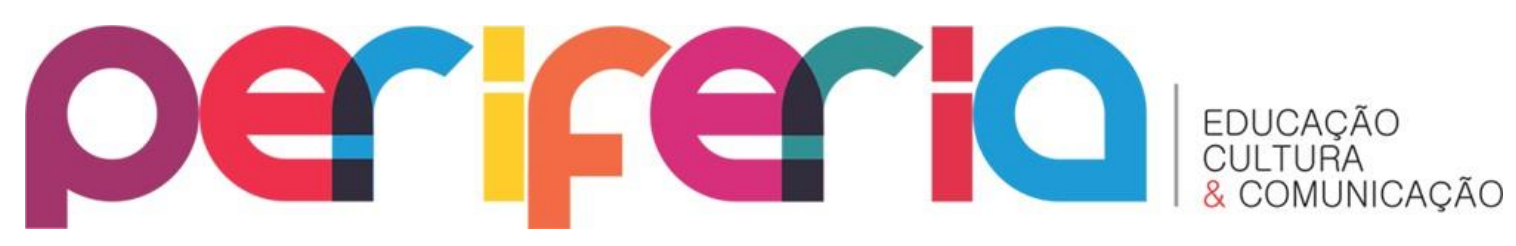

DISRUPTING SCHOOL LANGUAGE

\section{Abstract}

The school's point of view prevents from being in the troubles. But the school speaks in its problems, in the smallest, in its sides that can not be understood by the representational universe. Abandon school language and school's point of view; think about the outside, think about the presence of the non-school; recover what there is of movement, its sensitive texture, the plane of the unknown. Think of school as an effect, not as a premise. To open, from the formulation of some propositions, thresholds of investigation that do not become a prescription, but a project that investigates what is the common and what is educational.

Keywords: school language; school's point of view; the non-school 


\section{periferio}

Quisiéramos desarrollar una idea apelando a la forma proposicional. No es nuestra intención comprobar una verdad, ni permanecer en un método lógico de razonamiento. Se trata de un ejercicio del lenguaje, un trabajo en la economía discursiva. Una suerte de detención en el núcleo de una idea evitando la fuga verborrágica.

Una vez que formulamos una proposición, lo que sigue, más que su demostración fenoménica o, por el contrario, la exposición de una coherencia racional, es la puesta en juego de su consistencia. O mejor aún, de su cualidad problemática.

¿Son capaces las siguientes afirmaciones de abrir un umbral de investigación?

\section{PARA HACER HABLAR A LA ESCUELA NECESITAMOS ABANDONAR EL LENGUAJE Y EL PUNTO DE VISTA ESCOLAR}

Frecuentemente percibimos que el lenguaje que se dispara en automático discurre sobre las cosas y en ese acto las pierde. Como si en ciertas formas de habla se opacaran las sensaciones, los tonos balbuceantes, la inquietud que nace del vínculo sensible con eso que nombramos. Bergson solía decir que creemos que hablando sobre las cosas las comprendemos.

Tenemos la ilusión de que lo principal es discurrir sobre las cosas y que se las conoce cuanto más se habla de ellas. Pero sólo se comprende lo que puede reinventarse. (BERGSON, 2013)

Me pregunto si todo lo que se escribe, se elabora, se discute en relación a la escuela nos acerca a su vitalidad (lo que hay de vivo por inagotable ) o nos abrocha a un campo discursivo autonomizado de la cosa sobre la que se pretende intervenir. ¿Qué hay más allá de la representación? ¿Cómo hablar (de) algo sin que se nos pierda su textura sensible?

Podríamos no estar nunca en la escuela, podríamos prescindir de los encuentros con quienes la habitan, podríamos incluso no apelar a testimonios 


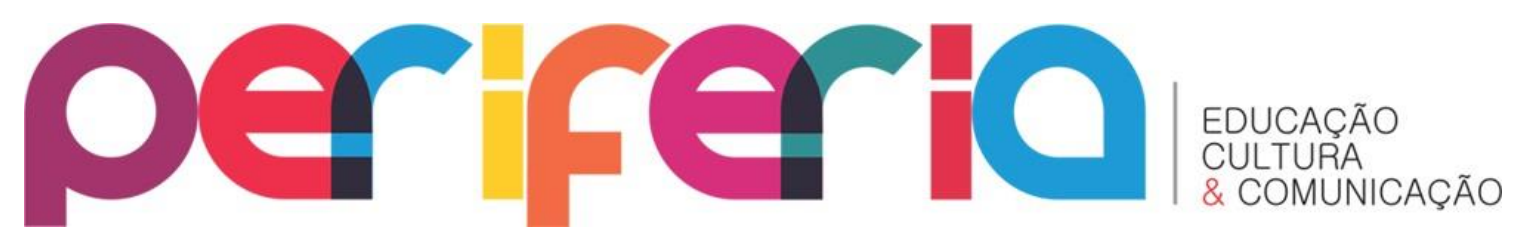

ni a situaciones concretas en los modos en que se afectan los cuerpos cuando viven la cotidianeidad escolar, y aún así sabríamos qué dice el nombre escuela y afirmaríamos su importancia, sus fracasos, su historia, sus logros, sus funciones, sus conflictos.

Tomados por el lenguaje escolar efectivamente podemos discurrir sobre la escuela. Digamos entonces que el lenguaje y el punto de vista escolar fabrican la escuela. Hablar sobre la escuela no es igual que hacer hablar lo que se mueve en esa constelación de fuerzas.

En pocas palabras, lo moviente de la escuela es ese punto en el que cae su Imagen consolidada. Cuando, al decir de Umberto Eco, los nombres ya no nombran la cosa que nombran, estamos en los verdaderos problemas, movidos por la sensación de incomodidad con una lengua que ya no habitamos. Recién en ese instante nos asomamos a un umbral de un pensamiento que sólo vive de (en) la inquietud. Por consiguiente cuando decimos lo moviente no hacemos referencia a desplazamientos físicos sino a esas pequeñas variaciones en las formas en que los cuerpos (cosas, sujetos) entran en relación. Pensar lo moviente es preguntarse qué pueden las cosas. $Y$ lo que pueden no está activo desde algún interior a develar, sino que requiere de alguna propensión que lo despliegue. Como las piedras que si bien tienen en su naturaleza la capacidad de rodar, sólo lo harán si se encuentran en un plano inclinado. El poder es entonces una relación y nuestra tarea consiste en poner a prueba heterogéneas maneras de configuración entre las cosas, a partir de conectar con sus posibles variaciones.

Hacer hablar a la escuela implica experimentar el plano de lo que desconocemos. Lo que conocemos no es sorpresa, sólo brújula de protección, control o inmunización. Lo que ignoramos, en cambio, toma la forma de pregunta. La cuestión, no obstante, es que la ignorancia (que no es de un saber en particular que no poseemos pero otro lo tiene) nos toma cuando estamos "desprevenidos" y abiertos a interrogar los modos en que somos afectados. La ignorancia es efecto de un choque involuntario que no se deja apresar en certeza alguna. 


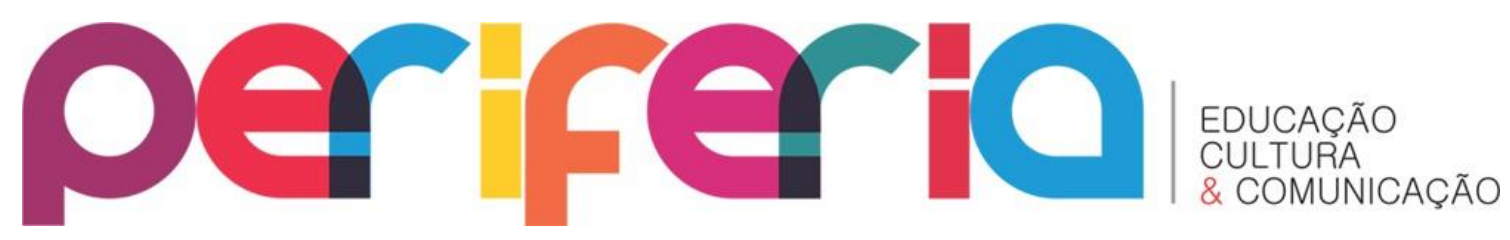

Siguiendo estas reflexiones sostenemos que la escuela habla en lo ínfimo, en sus costados inentendibles para el universo representacional. En los cambios y mutaciones que el "saber" ignora porque están afuera de los modelos de visibilidad e inteligibilidad.

Dice Godart, "Cómo decir lo que pasó. Por qué todas esas señales que están entre nosotros terminan por hacerme dudar del lenguaje y me inundan de significación ahogando lo real en lugar de liberarlo de lo imaginario." (LAZARATTO, 2006)

Una profesora da clase en un quinto año. Un grupo de jóvenes habla por celular, otro aprovecha para completar un cuadernillo del curso de ingreso a la universidad. Y otros tantos la increpan preguntando "¿para qué nos sirve lo que enseñás?". La docente relata esta situación para demostrar el desinterés de sus alumnos. La profesora se encuentra desmoralizada. Lo que encuentra no le hace pregunta. Ella no encuentra, constata una desilusión.

La escuela "habla" en sus problemas. Y sus problemas lo son cuando escapan de una visión del déficit. Los pibes calculan cómo zafar del hastío, calculan lo que podrán hacer luego si aprovechan ese tiempo plano adelantando tareas. ¿Es el cálculo una nota de la subjetividad contemporánea? ¿Podría la profesora compartir esta pregunta con sus alumnos? ¿Todo es pasible de cálculo? ¿Hay algo para investigar en este terreno?

En consecuencia, si el punto de vista escolar opaca la dimensión problemática que emana de encuentros inesperados y "oscuros" (de una primera oscuridad dada por su costado ilegible en las coordenadas de los sentidos familiares), impide así mismo la posibilidad de elaborar un pensamiento de la pregunta en torno del poder de la experiencia educativa.

\section{EL PUNTO DE VISTA ESCOLAR IMPIDE UN PENSAMIENTO DE LO EDUCATIVO}

¿Es posible abandonar el punto de vista? Tal vez no sea la mejor pregunta porque la respuesta es obvia: no. ¿Es posible, en cambio, advertir la 


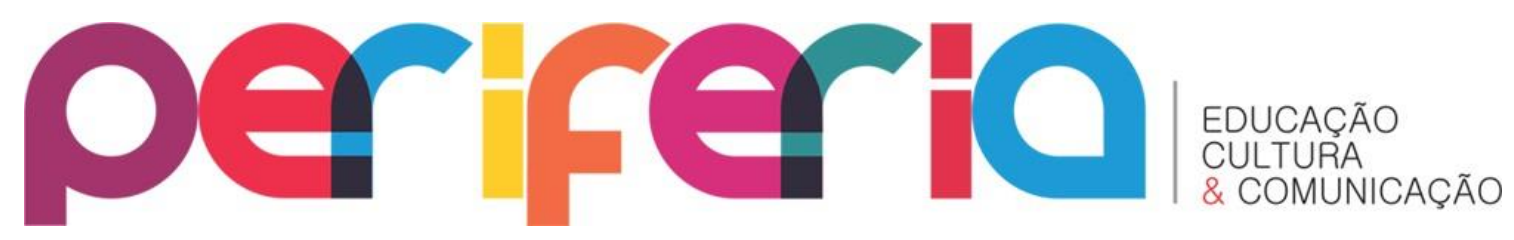

fijeza del punto de vista y a su vez el flujo de corrientes que se abren cuando simpatizo con el movimiento de las cosas?

Pensemos lo siguiente: ¿da igual definir a la escuela que interrogarla desde cierta "ingenuidad"? Si sé qué es una escuela no podré evitar enjuiciar lo que en ella sucede según se acerque o se aleje de sus atributos sancionados.

Corridos de este lugar, no por moda sino por ineficacia, los gestos que se abren son de otro tenor... estoy en la escuela, me afecta esto que ocurre pero no logro apresar un sentido, no lo entiendo, no sé qué hacer. Tomo nota de mis impresiones, lo charlo con otros, pruebo tal o cual cosa, pesco algún hilo desde donde tirar, observo sus consecuencias, sus derivas. Se trata de otro lenguaje, de otra percepción, de otro modo de estar en los problemas.

El lenguaje escolar es el lenguaje que enfatiza (en exceso) el punto de vista. El obstáculo mayor ni siquiera es el punto de vista sino olvidar que lo es, que sólo da cuenta de una perspectiva. Cree nombrar la cosa (la escuela en sus diversas dimensiones y performances) pero sólo nombra lo que quiere de la cosa.

El lenguaje del punto de vista (escolar) sustituye las cosas por los conceptos. El inconveniente no es el concepto sino la sustitución. Cuando el concepto borra la inquietud por las cosas, sólo cobra relieve la imagen congelada que la designa. A diferencia, cuando elaboramos una idea que contiene o expresa la dinámica de las situaciones más que clasificar o pretender alcanzar una síntesis de sentido, el concepto viene a liberar nuevas potencias. Cuando un concepto nace de un sentir libera una potencia imaginativa al tiempo que permite niveles de elaboración de la experiencia que amplían nuestro poder de comprensión. Cuando en cambio nace de una entelequia se separa del plano de las afecciones.

Decimos no escolar (DUSCHATZKY y SZTULWARK, 2010) y más que una definición que captura el sentido de alguna cosa lo que hacemos es afirmar la potencia de los lenguajes y percepciones no escolarizadas que están en la escuela. No escolar es entonces la pregunta por explorar las resonancias 


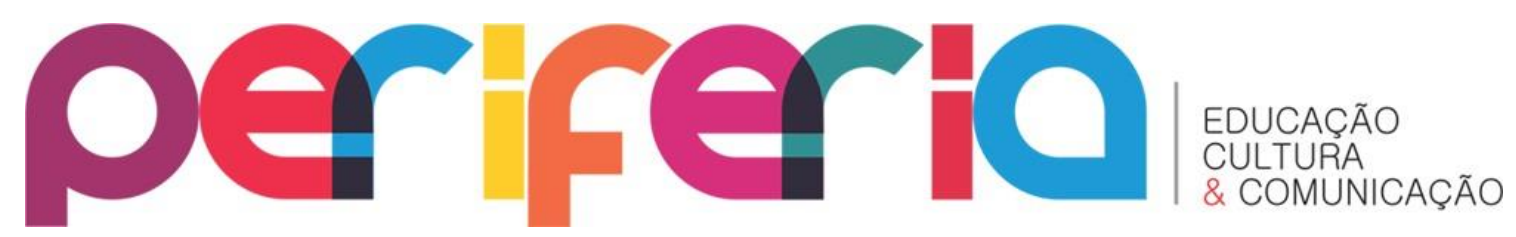

educativas de modos múltiples de configurar escenas de aprendizaje. No escolar es estimar el valor de modos de hablar, sentir y actuar no prefigurados.

Encerrados en la lógica del punto de vista, más que experimentar confirmamos una imagen previa saturada de sentido.

El movimiento no se observa ni se evalúa: se experimenta. ¿Qué sería experimentarlo? Sentir-pensar sus mutaciones. El sentir no es mero sentimiento personal. Sentir es apreciar las resonancias sensibles. Apreciar sin juicio, apreciar más allá del bien o el mal. Apreciar es otorgar valor al mundo de las afecciones y seguir las pistas de sus consecuencias. Tarea que lejos de cualquier pasividad exige un trabajo de sutil escucha.

En el movimiento hay simpatía (contacto con lo singular), en el punto de vista hay juicio. Por eso el punto de vista necesita de evaluaciones, archivos, biografías. El movimiento necesita preguntas. El punto de vista quiere conocer; lo moviente, en cambio, pide expandirse.

La intuición necesita de un lenguaje fiel a lo moviente. La intuición no es una mera forma de acceso inmediato a las cosas, no es un sentimiento repentino e iluminado, no es una facultad esotérica o una vaga inspiración. La intuición es un acto simple que recorre las sinuosidades de lo real acompañando un movimiento no forzado de actualización de multiplicidades. Percibir, estando en las cosas, por dónde viaja una fuerza que podría tomar formas nuevas de expresión.

El punto de vista requiere de un lenguaje abstracto y significante. La intuición navega mejor en un lenguaje minimalista, agujereado, inquietante.

\section{PENSAR LA ESCUELA ES PENSAR EL REAL DE SU EXISTÊNCIA}

Podríamos decir que la función es la función del punto de vista (estatal -no necesariamente privativo del estado). La función está en el origen. La función opera sobre las cosas y no entre ellas. Pensar la escuela en los albores del siglo XX era un problema que se realizaba ejerciendo funciones, roles, 


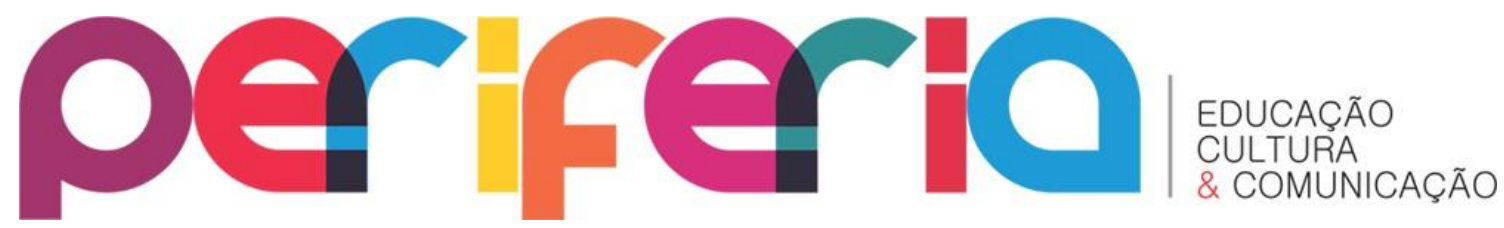

operatorias. La escuela no era por fuera de la función. Había un "afuera" neutralizado por la función, en consecuencia "escuela" era efecto de "función".

El "afuera" lo es de lo pensado. En ese sentido, se trata de una potencia, de una diferencia pujando, abriendo surcos. El afuera es la presencia de lo no escolar y la escuela hoy no es sin eso. Porque sólo hay escuela como experiencia si somos capaces de imaginar nuevas formas de configuración que no se modelicen.

Escuela secundaria de gestión estatal del conurbano bonaerense. Juan es el más chico de varios hermanos. Los profesores rumorean que la familia es parte de una banda que roba. Juan los enfrenta y acusa de ser caretas, sale de la clase, va al patio, entra a otras aulas. En una ocasión se peleó con la secretaria, ella le dijo delincuente, él le dijo paraguaya. Ella se dio vuelta y lo enfrentó diciéndole: "no te tengo miedo", él se enojó y dio un puñetazo a la pared. Se lastimó los nudillos y la sangre manchó la pared. Más tarde un alumno encerraría en un círculo azul a la mancha de sangre. Directivos e inspectores determinaron que el alumno siguiera concurriendo a la escuela pero desde afuera. Que no entre. Que los docentes prepararan material para que haga en su casa y todos los días los traiga completos. La secretaria siguió adentro, Juan quedó afuera.

Llegaba a media mañana, se colgaba de la reja y comenzaba a aplaudir hasta que alguien lo escuchaba, los chicos lo iban a ver a la puerta. El equipo empezó a salir de la escuela a su encuentro, entonces se conversaba en la esquina sobre diferentes cosas, se tomaba mate con galletitas, él trajo a sus amigos que no estudiaban. Algunos compañeros que no llegaban al horario de entrada se sumaban en la esquina. El alumno que marcó la sangre de la pared dijo: "lo hice para que todos vean que aquí alguien salió lastimado".

El director consideró que su mala conducta ameritaba el bloqueo de la netbook. Después de eso, una mañana fría de mármol, el director irrumpió en el espacio que el EOE ocupa en la escuela, queriendo hablar pero sin lograr emitir sonido. Sus nervios provocaban un cuadro de desesperación ante lo que parecía una urgencia inminente. Al igual que los bomberos, el EOE acudió en su pedido. En el medio del patio estaba él. Un señor imponente. Con $4^{\circ}$ de temperatura, él estaba en remera 


\section{periferio}

que enunciaba su admiración por un cuadro de fútbol. Bermudas, zapatillas y un gorro en la cabeza que dejaba escapar una cabellera prominente y enrulada. Detrás de él, se asomaba tímidamente la cara de Juan. El padre se presentó como "borracho del tablón"2. Una integrante del EOE preguntó: “¿Usted está en los entrenamientos?” A lo que el padre de Juan respondió: "Sí, siempre estamos con los muchachos". La integrante continuó su interrogatorio: "¿Y lo ve a Ramón Díaz? El señor contestó: "Sí, todos los días". Juan sonrió y preguntó: “¿Te gusta Ramón Díaz?". La integrante le dijo: "Shhh”. Juan empezó a cantar: "Le gusta, le gusta". El padre preguntó: “¿Quién es esta señora, nene?”. Juan respondió: "Es con la que hablo y me da la tarea". "Ahhh, señora, mucho gusto, yo estoy enojado, voy a reventar la escuela, pero con ustedes no es la cuestión". La integrante lo quedó mirando. El señor sacó un boleto de su bolsillo, y le dijo: "Anote su celular aquí que se lo doy a Ramón para que la llame". La integrante anotó su número de celular. El padre sonreía y estaba más tranquilo. Ingresa a la dirección y se abre una conversación con el director y algunos del equipo.

Al comienzo de la charla, se entabló una discusión entre ambos, que luego llegó a pequeños acuerdos, uno fue el desbloqueo de la netbook, acción esta que presenció el padre. La otra fue el pedido por parte de la familia sobre la presencia del alumno en la escuela. El director comentó que ese tema estaba en revisión. Cuando todo volvió a la calma, la familia se retiró del lugar, la secretaria salió detrás de un mueble y sin mediar palabra, se puso a trabajar.

A fin de año, después de diversos acuerdos intrainstitucionales, el $90 \%$ de los profesores desaprobó a Juan por considerar que sin presencia en la escuela, los alumnos no aprenden." (BALOSSI, 2014)

Imposibilidad de estar en lo moviente, el obstáculo del punto de vista escolar está en la impotencia de estar en los problemas que como tales no se formulan en términos de déficits.

El real de la existencia no es la mera realidad de lo que sucede (pibe que insulta, director asustado, padre que increpa). El real de la existencia es lo moviente, la cualidad mutante de lo que sucede. Es la profesora que frente

2 "Los borrachos del tablón" se le llama a la barra brava del equipo de fútbol argentino River Plate. 


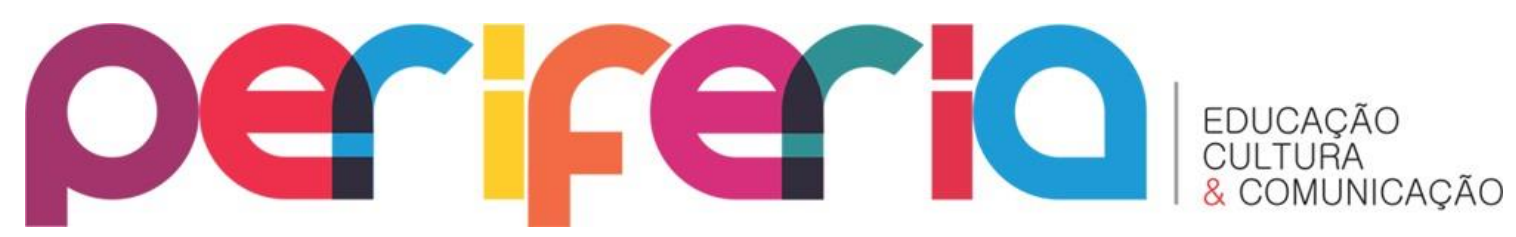

al padre temible lo ataja con la complicidad de Ramón Díaz ${ }^{3}$. Son los virtuales que podrían actualizarse, aquellas señales de potencia que puestas a trabajar efectúan procesos de diferenciación.

Pensar el real de la existencia es pensar campos de posibilidad que no están en ninguna mente sino en las mutaciones efectivas que bajo ciertas condiciones pueden generar nuevas configuraciones sociales. Lo real de la existencia se capta intuitivamente. Para lo cual es necesario violentar las categorías o los puntos de vista totalizantes. La realidad de la existencia necesita conceptos, pero aquellos nacidos de un sentir, de una tensa atención a lo que pueda desplazarse, derramarse. Conceptos fluidos capaces de hacer parir nuevas fuerzas.

\section{LA EDUCACIÓN ES EFECTO SIN PREMISSA}

¿Podríamos pensar la enseñanza como el camino hacia la conquista de problemas? Enseñar es aprender a leer el mundo. Y leer el mundo no es significarlo sino hacer que podamos estar más activamente entre las cosas que vivimos. Leer el mundo no supone atribuir sentidos, ni caer en resignadas aceptaciones ni abrazar exaltaciones futuristas. Leer el mundo es leer las fuerzas de éxodo y barajar en complicidad las formas de gestionar sus posibles.

Los efectos sin premisas son pensables, nunca evaluables en relación a una referencia exterior. Se perciben en las transformaciones vitales. Contienen valores que sólo valen en las singularidades de una situación.

La educación sucede en el medio de una pregunta que se efectúa. Educación es investigación. Hay educación si hay problemas a investigar.

Y así como la pregunta en tiempos de Estado Nación se realizaba mediante sofisticados aparatos de producción subjetiva, hoy se trata de

3 Ex futobolista argentino y entrenador del equipo de fútbol River Plate entre los años 2012 y 2014. 


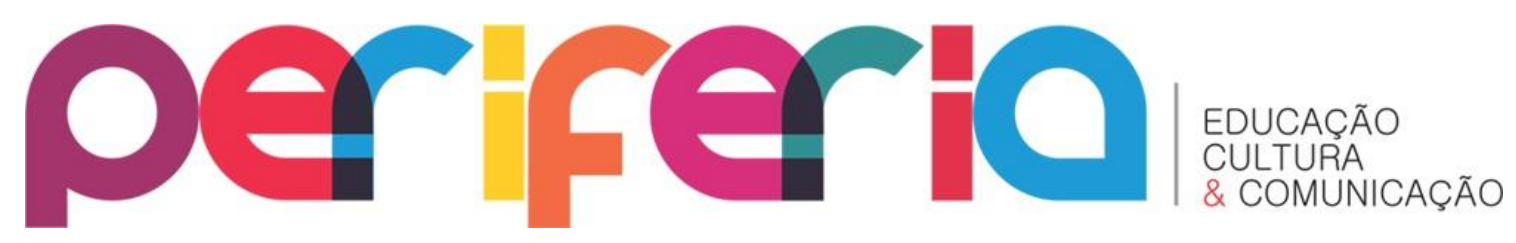

preguntas a efectuarse (la diferencia radica en que la realización es de una única imagen y la efectuación admite heterogeneidad de imágenes que sólo se elaboran al calor de la experiencia). La pregunta es microscópica y su politicidad se enraiza en quienes están ahí tomados por un profundo desconcierto.

¿Qué se efectúa? Efectuar una pregunta no es buscar una respuesta puntual ni aplicar un principio rector; una pregunta se efectúa si crea planos de diferenciación.

Cuando implementamos una solución a lo que definimos como problema podemos advertir si su planteamiento fue certero. No por haber hallado la solución mágica que devuelve una ilusión de orden a un supuesto desorden, sino porque logramos abrir un plano sensible de creación, de movilización de fuerzas que ponen en escena nuevos planos de relación. Probablemente "la solución" ponga en evidencia nuevas preguntas, nuevos encuentros, nuevos hallazgos, nuevas inquietudes, nuevas realidades que se distancien de lo que creíamos era el móvil que buscábamos. Lo interesante de los problemas radica en la capacidad de experimentar variaciones. Un buen problema es el que nos abre a una variación en los modos de percibir, sentir, actuar, pensar.

Volvamos a la pregunta por la efectuación. La escuela efectúa (no realiza) la pregunta por lo común. Si se tratara de una realización sólo deberíamos bregar por restituirla como aparato de producción de sujetos a imagen y semejanza de una moralidad comunitaria. Si en cambio pensamos la efectuación, no sabemos de qué se trata esta experiencia de vivir juntos y lo que hacemos es investigar sus formas. Podríamos enunciarlo así: la escuela es el territorio en el que se pone a prueba lo común de la existencia. Afirmo y al mismo tiempo, en la afirmación, pregunto. ¿De qué se trata lo común? Me adelanto a decir que lo común no se juega en identidades, ni en comunidades de sentido. 


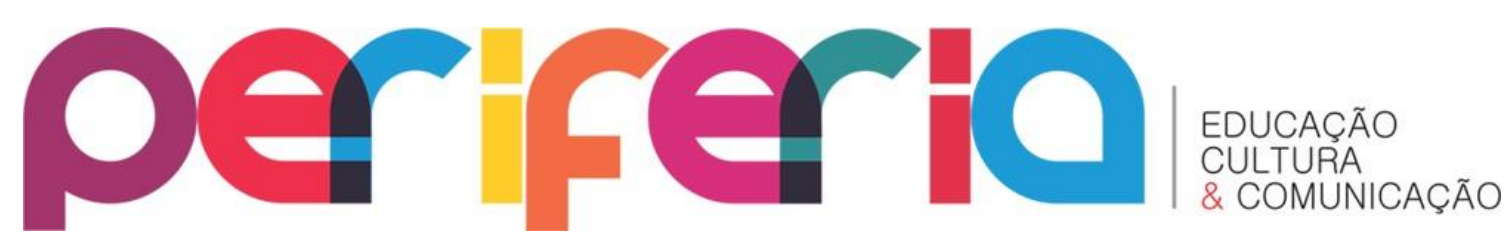

Un ejemplo. En Rosario, más exactamente en uno de sus barrios de mayor precariedad social y económica, funciona hace cinco años una escuela de adultos que es una experiencia de autogestión popular ${ }^{4}$.

Esta experiencia nace de una pregunta que a su vez se inscribe en una lucha del barrio amenazado por la topadora inmobiliaria que pretendía arrasarlo en pos de la construcción de un barrio cerrado. Esta movida que permitió frenar el "emprendimiento empresarial" puso en escena lo que puede una fuerza social. El poder colectivo no tiene meta sino problemas que van creciendo en su efectuación, en su puesta a prueba. De la defensa del territorio a la afirmación de modos de vida. En esa dinámica surge la idea de pensar modos de trabajo que alteren las habituales y desgastantes formas de la cotidianeidad. Es la lucha reivindicativa lo único que hace a un común?. No habría en las formas complejas de gestión y multiplicación de fuerzas un interrogante que sobrepasa la demanda?

No estamos frente a una escuela alternativa. Lo que tuvo lugar es la experiencia afirmativa de investigar el poder de lo colectivo que se expresa en un territorio escuela. La escuela se llama ETICA -Escuela Territorio Insurgente Camino Andando-. Nombre extenso pero que nos dice que puede haber escuela no sólo en el origen de un proyecto fundacional sino en el medio de una invención situacional. Esta experiencia expresa una política de gestión que es una política que pone a prueba modos de hacer relación social en territorio. La escuela es uno de los modos en que esa existencia toma forma. Escuela con profesores, sin directivos, con estudiantes, con asambleas que toman las decisiones de gestión, con preguntas que se abren cada vez que acontece algo que no saben cómo pensar.

Recuerdo la siguiente escena:

En una de las salas están discutiendo sobre la salud. Cada uno dispone de una fotocopia en la que logro ver

$4 \quad$ En el apartado "No hay escuela en su nombre sino en su relación" (DUSCHATZKY, 2017) nos metemos profundamente con esta experiencia. 


\section{periferio}

cuadros de doble entrada. Salud tecnocrática, neoliberal, de un lado... no alcanzo a distinguir qué dice del otro. Hasta el momento, la cosa navegaba por los ejemplos que constatan, una y otra vez, la precariedad sanitaria extrema sepultada por la falaz difusión mediática que convoca a los habitantes a cuidar el medio ambiente, mientras las aguas contaminadas y la basura contaminante siguen poblando el paisaje. De repente, irrumpe un comentario, una de las estudiantes acota: "Esto que hacemos acá, esta escuela, ¿no es caso salud?

Ese comentario expresa el valor de la experiencia de ETICA. No es la brillantez de una persona individual la que mediante esa interrupción desplaza la discusión de la salud -sólo encerrada en los criterios de enfermedad o sanidad de un cuerpo físico- a la imagen de un buen vivir social, sino la expresión de que algo flota en una atmósfera colectiva como para que un pensamiento se active imaginando nuevos modos de nombrar el devenir de una existencia que se gesta en relación. Entonces, salud como experiencia de otro posible en las relaciones sociales, salud como la pregunta que efectúa un buen vivir que nunca se clausura en un saber. Un nuevo modo de conocer lo que podemos.

La escuela sería entonces no una premisa sino un efecto, no una función determinada por fuera de una dinámica social sino la territorialización de una pregunta que se pone a trabajar. Ya no la verificación y reproducción del punto de vista escolar devenido prescripción sino un proyecto que investiga de qué se trata lo común y de qué lo educativo.

\section{LA EDUCACIÓN ES INVENCIÓN “NO CREATIVA”}

Llame ya. ¿Cómo sustraerse de las promesas que nos ofrece el mercado? Sprayette nos muestra cómo cocinar fideos prescindiendo de ollas y fuegos. Sólo agitando un frasco de vidrio Ud. podrá evitar la engorrosa tarea de la limpieza grasulienta que se nos impone luego de una cena familiar. Un simple 


\section{periferio}

dispositivo eléctrico unido al recipiente transparente, facilita la vida de las amas de casa. Creatividad pura.

El mercado es creativo para seguir siendo lo mismo (flujos conectivos de consumo y circulación del capital). Creatividad para asegurar la preservación de una vida mercantilizada. Creatividad como imperativo de un sujeto cada vez más empresario de sí mismo. Creatividad para no quedar afuera de la adrenalina vertiginosa del deseo de obtener. Creatividad como rasgo de originalidad. Creatividad como cualidad de individuos exitosos. Creatividad como medio para obtener otra cosa. $\mathrm{Y}$ cosa que echada al consumo borra el espíritu sensible que la gesta.

Recorramos otros costados de la idea de creación. Necesitamos imaginar el acto creador por fuera del imperativo creativo, lo necesita nuestro agotamiento frente a la verborragia que reivindica por doquier la panacea de la creatividad. Lo necesita nuestra desconfianza a la exigencia de una vida sobresaliente. Lo necesitan nuestras microexperiencias que piden otro nombre porque aquel fue sustraído de una materialidad palpable de la experiencia de invención.

Se trata de una fuga del bello mundo Truman show cuya maqueta de vida intenta atraernos a un ideal (siniestro) de felicidad. ¡Sé creativo! Cambia tu vida, tú puedes. Una suerte de panacea exudando autoayuda que confunde vitalismo con jolgorio de una vida buena onda, mediatizada, opulenta, brillante, de una exposición ejemplar.

La creatividad se impone como abstracción y representación aspiracional. La creatividad se verifica en las respuestas (“novedosas”), en la fabricación de objetos llamativos cuando no hipnóticos.

La creación en la que queremos pensar es la que expresa el continuo afecto-cosa-idea. El valor de la creación no estaría en la mercantilización del objeto o en su espectacularización. El valor de la creación se verifica en la mutación de la existencia.

La Ética es creación no por su costado de escuela alternativa. No lo es por la voluntad innovadora de un grupo de sujetos. Tampoco medible por sus 


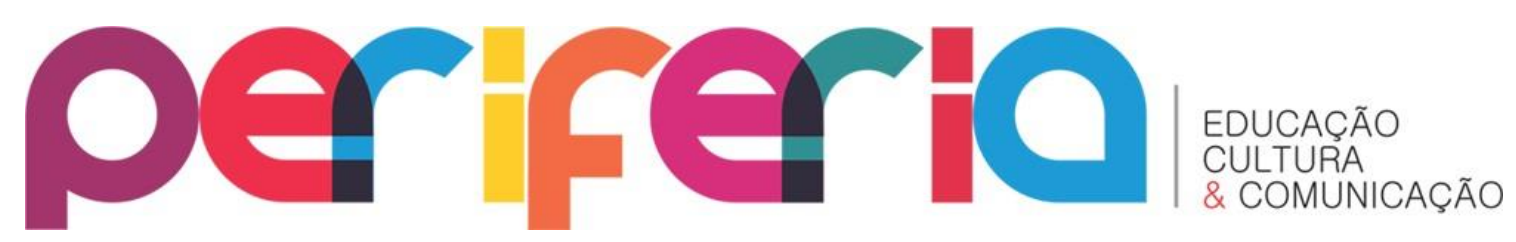

éxitos ni permanencia. Lo es porque los cuerpos que la hacen son otros y otras sus relaciones cuando sus sensibilidades e imaginaciones se bifurcan en el medio de problemas.

Sólo somos problemas, estamos en problemas, compartimos un común malestar o una afinidad inquietante que si se pone a pensar conquista otras temporalidades y cualidades relacionales. La creación como un campo de fuerzas sostenida en una pregunta despojada de moralidad alguna.

La creación es inmanente al problema, la creatividad es un recurso para sobresalir. La creación es involuntaria, anónima, afecta los modos de vivir. Nace de una incomodidad devenida poder social.

\section{REFERENCIAS}

BALOSSI, Sandra. “Desde Afuera”. Revista Tráfico de experiencias, Buenos Aires, $\mathrm{N}^{\circ} 2$ 2, 2014. Disponible en: http://t-d-x.com.ar/a/article/desdeafueral

BERGSON, Henri. El pensamiento y lo moviente. Buenos Aires: Editorial Cactus, 2013.

DUSCHATZKY, Silvia; SZTULWARK, Diego. Imágenes de lo no escolar. Buenos Aires: Editorial Paidós, 2010.

DUSCHATZKY, Silvia. Política de la escucha en la escuela. Buenos Aires: Editorial Paidós, 2017.

LAZARATTO, Maurizio. Por una política menor. Madrid: Traficante de Sueños, 2006. 